Revista

ACor

das Letras

\title{
Português e Redação: imprecisão de duas disciplinas de uma disciplina só
}

\author{
Portuguese and Writing: imprecision of two disciplines of a single discipline
}

\author{
Ligia Pellon de Lima Bulhões \\ Universidade do Estado da Babia \\ Salvador, Bahia, Brasil \\ Lívia de Carvalho Mendonça \\ Universidade do Estado da Babia \\ Universidade Estadual de Feira de Santana \\ Feira de Santana, Bahia Brasil
}

Resumo: Abordamos neste artigo a imprecisão dos currículos do Ensino Fundamental II regular de escolas públicas baianas que ofertam as disciplinas Redação e Língua Portuguesa, ou apenas Língua Portuguesa. Baseamo-nos em entrevistas feitas com professores de português da rede pública de educação do Estado da Bahia que atuam neste nível de ensino. Perguntamos que questões sobre a língua e os conteúdos de português estão na base desta imprecisão curricular. Citamos documento e autores que conceituam a língua de acordo com os seus aspectos discursivos e enunciativos, e não apenas em função de suas formas composicionais. Concluímos que as incongruências dos currículos para o ensino de português refletem os defeitos dos objetivos do ensino do português que estão postos pelo sistema escolar e que se confundem na imprecisão de duas disciplinas ou uma disciplina só.

Palavras-Chave: Língua Portuguesa. Redação. Gramática. Texto. Ensino.

Abstract: We approach in this article the imprecision of the curricula of Elementary Secondary Education of Bahian public schools that offer the subjects of Writing and Language Portuguese, or Portuguese Language only. We are based on interviews with Portuguese teachers of the public education network of the State of Bahia who work at this level of education. We ask that questions about the language and contents of Portuguese are the basis of this curriculum imprecision. We cite document and authors that conceptualize the language according to its discursive and enunciative aspects, and not only in function of its compositional forms. We conclude that the incongruities of the curricula for Portuguese teaching reflect the defects of the objectives of Portuguese teaching that are placed by the school system and that are confused in the imprecision of two disciplines of a single discipline.

Keywords: Portuguese Language. Essay. Grammar. Text. Teaching.

* Universidade do Estado da Bahia - UNEB, Salvador- Bahia, Brasil. E-mail: ligiapellon@gmail.com.

** Universidade Estadual de Feira de Santana- UEFS, Feira de Santana - Bahia, Brasil. E-mail: livinhamendonca@yahoo.com.br 


\section{INTRODUÇÃO}

Abordamos, em linhas gerais, neste artigo, a imprecisão dos currículos do Ensino Fundamental II regular de escolas públicas baianas que ofertam aleatoriamente as disciplinas Redação e Língua Portuguesa, ou apenas Língua Portuguesa.

O que nos motivou a compor o artigo foram entrevistas feitas neste ano com nove professores de português que são estudantes do Mestrado Profissional em Letras (ProfLetras), do Departamento de Letras e Artes da Universidade Estadual de Feira de Santana - UEFS / Bahia. Elas compõem a primeira etapa da pesquisa em andamento intitulada Escritas, contextos e escola na voz de professores de escolas públicas da Bahia, desenvolvida por Ligia Bulhões, e que é parte do estágio pós-doutoral que ela realiza nesse Departamento.

Esta pesquisa situa-se no campo amplo dos estudos sobre cultura escrita, no âmbito das ideologias linguísticas. Diz respeito às manifestações contemporâneas de escrita que constituem diferentes contextos discursivos da vida cotidiana, escolares e não escolares, concretizadas em textos inscritos em diferentes gêneros do discurso, inclusive os midiáticos da era digital. Ou seja, o ponto de vista do estudo é o da escrita enquanto conjunto sócio-histórico de práticas, na perspectiva dos letramentos e multi/hiperletramentos. E do texto como enunciado concreto, de acordo com a perspectiva sócio-histórica e dialógica para o estudo dos gêneros do discurso da herança bakhtiniana, dentre outros aportes teóricos que se façam necessários no decorrer da investigação.

Para a primeira etapa do estudo, traçamos, como objeto, a elaboração de um perfil sociolinguístico dos mestrandos entrevistados, que são professores da área de Letras do Ensino Básico e que moram e lecionam em cidades do interior baiano, a partir do relato tanto de suas experiências cotidianas de leitura e produção de textos não escolares, quanto de atividades com textos escritos que compõem a sua prática docente em aulas de português.

Argumentamos que o que os professores dizem sobre estas atividades revela, em linhas gerais, a concepção de língua e, especificamente, de escrita que mantêm no seu trabalho diário em sala de aula. E que está na base dos objetivos do ensino de português que na prática adotam e da avaliação que fazem de si enquanto professores e de seus alunos. Enfim, assumimos que esses dados podem nos dar pistas sobre as relações necessárias ou possíveis conflitos entre um domínio teórico e um domínio prático sobre a língua.

Fizemos uma média de duas entrevistas temáticas com cada um dos nove professores nas dependências da UEFS, em dias de aulas do mestrado. Utilizamos o gravador digital como instrumento de pesquisa e mesmo alguns contatos por aplicativos digitais, quando necessário. E, durante a transcrição desses dados, nos chamou a atenção o que os professores nos informam sobre a divisão aleatória e alternativa de conteúdos da Área de Língua Portuguesa, que são distribuídos em uma ou mais disciplinas presentes nos currículos do Ensino Fundamental II de escolas públicas baianas. 
Observamos que há disciplinas diferentes com um objeto comum, que é o texto escrito, e que compartilham os objetivos de formar leitores e redatores eficientes, o que acarreta sobreposição de conteúdos se elas não forem planejadas para ser complementares. Nesse contexto, a disciplina denominada Redação, Produção Textual, Letramento Linguístico ou Linguagem e Comunicação pode ou não dividir o currículo com a disciplina Língua Portuguesa, a depender dos currículos das escolas públicas estaduais ou municipais. O que nos leva a perguntar: o que motiva essa imprecisão curricular?

\section{PROFESSORES, ESCOLAS E DISCIPLINAS}

Os professores em suas entrevistas reconhecem que a realidade curricular da Área de Língua Portuguesa mencionada acima é fruto de decisões vindas do sistema escolar às quais precisam se submeter, o que muitas vezes cria problemas na divisão dos conteúdos a serem abordados em classe.

Consideramos oito professores entrevistados, que são os que estão lecionando atualmente no Ensino Fundamental II. Seis mulheres e dois homens com idades que variam entre trinta e um e quarenta anos. Eles têm de dez a de dezessete anos de experiência como professores de português do Ensino Básico em escolas públicas do interior baiano, o que perfaz uma média de 13 anos de docência em Língua Portuguesa. Dão aulas para alunos do sexto ao nono ano, sendo que três são professores de um ano apenas, dois professores lecionam em dois anos, um em três anos, e um outro em quatro anos desse nível de ensino.

Três entrevistados são professores apenas da rede municipal, quatro apenas da rede estadual, e um atua nas duas redes de ensino público da Bahia. Dos cinco professores da rede estadual, três lecionam no município de Feira de Santana - sendo que um em escola de tempo integral; um no Distrito de Juazeirinho, em Conceição do Coité; e um no distrito de Bonfim de Feira, na Região Metropolitana de Feira de Santana. E dos quatro professores da rede municipal, um leciona em Caldas do Jorro, no município de Tucano; um na localidade de São José, no Distrito de Maria Quitéria; um na cidade de Amélia Rodrigues; e um nos municípios de Rafael Jambeiro e Terra Nova. As quatro últimas localidades situam-se na Região Metropolitana de Feira de Santana.

Das cinco escolas municipais consideradas, a do município de Maria Quitéria oferece a disciplina Produção Textual em sua grade curricular do Ensino Fundamental II com carga horária própria, separada de Língua Portuguesa, e conta com professores diferentes nas duas disciplinas. Segundo a professora entrevistada, que assume Produção Textual nessa escola, houve mudança com a reformulação da grade curricular, e esta disciplina "é Língua Portuguesa, como se fosse Redação". E os mesmos textos são utilizados por ambos os professores com base em planejamento pedagógico comum.

Nessa mesma estrutura curricular, a escola municipal de Amélia Rodrigues oferece as disciplinas Língua Portuguesa e Redação e, segundo uma das mestrandas entrevistadas que leciona a primeira disciplina no oitavo ano e a outra no nono ano, os professores utilizam os mesmos textos em ambas. Sendo que, em linhas gerais, os conteúdos de 
Língua Portuguesa contemplam aspectos gramaticais do texto já estudado antes, enquanto em Redação o foco é em leitura e produção de textos. "Tem questionamento por isso em AC (Atividades de Classe)", informa a professora, referindo-se às dificuldades de planejamento de conteúdos que essa divisão cria entre professores da área de língua portuguesa.

Já as escolas municipais de Rafael Jambeiro, Terra Nova e de Caldas do Jorro, em Tucano, oferecem apenas Língua Portuguesa para alunos do Ensino Fundamental II.

Das cinco escolas estaduais consideradas, três contemplam Língua Portuguesa além de Redação ou Letramento Linguístico no currículo do Ensino Fundamental II. Duas são de Feira de Santana, e segundo uma professora que leciona Redação e Língua Portuguesa em anos distintos em uma escola desta cidade, Redação é mais sobre gênero textual, e Português incorpora conteúdos de gramática. Ela conta que tenta fazer um trabalho interdisciplinar centrado em textos e critica professores de outras disciplinas que oferecem resistência à proposta. Argumenta que Português, Redação e Literatura são de um mesmo eixo, mas que, em algumas escolas, estão em eixos diferentes. Afirma que Língua Portuguesa deve se centrar em textos e que vê gramática "não como um fim”, tanto que trabalha as estruturas gramaticais dos textos produzidos pelos alunos.

A outra escola estadual de Feira de Santana, com o mesmo perfil curricular para o ensino de língua, funciona em turno integral. No Ensino Fundamental II, essa escola oferece as disciplinas Letramento Linguístico e Língua Portuguesa, sendo que o professor da escola que entrevistamos nos esclarece que Letramento Linguístico é a mesma coisa que Leitura e Produção de Textos, e faz parte do Projeto Mais Educação, implantado em escolas estaduais de Feira de Santana que oferecem ensino integral para funcionar como reforço para Redação. Esse professor leciona as duas disciplinas para alunos do sexto ano e não diferencia Língua Portuguesa de Literatura e de Redação, afirmando que "tem que haver interdisciplinaridade". Acrescenta que o objetivo de Língua Portuguesa é ensinar a ler e escrever e que o estudo da gramática deve partir do texto e a ele retornar. Cita como exemplo o aprendizado dos adjetivos, que é "um saber vinculado à redação adequada de um período". E que "uma oração subordinada precisa de uma principal”.

A terceira escola estadual a oferecer Linguagem e Comunicação, além de Língua Portuguesa, para alunos do Fundamental II, é a do Distrito de Bonfim de Feira. A professora entrevistada dá três aulas semanais de Língua Portuguesa e duas aulas de Linguagem e Comunicação para uma mesma classe do nono ano. Esta última disciplina, segundo a docente, “[...] é a mesma coisa que Língua Portuguesa, mas 'eles' dizem que é como se fosse Redação, a parte de produção, é dividido [...]”. Linguagem e Comunicação seria, ao seu ver, mais "para essa coisa de gênero e produção, avaliação de escrita"; teria "mais leveza", pois não tem "compromisso" com a gramática tradicional. Conta que já trabalhou no nono ano com "gêneros, metáforas, poesia" etc, e "saíram coisas bacanas". Ao mesmo tempo, afirma que "Linguagem e Comunicação é praticamente Português".

Já uma escola estadual de Feira de Santana e outra do Distrito de Juazeirinho, região de Conceição do Coité, só oferecem a disciplina Língua Portuguesa no currículo do Ensino Fundamental II. 


\title{
ENSINAR PORTUGUÊS PARA QUÊ?
}

Os professores do Ensino Fundamental II regular que atuam em disciplinas distintas, nos dizem, em suas entrevistas, que tanto em Língua Portuguesa quanto em Redação, ou disciplinas correspondentes, os conteúdos trabalhados em classe centram-se em textos, como unidade de ensino, tendo o professor como meta principal ensinar os alunos a lê-los, compreendê-los criticamente e redigi-los.

Esses objetivos fazem parte das diretrizes curriculares estabelecidas pelo sistema de ensino para a Área de Língua Portuguesa, estão presentes na formação docente desses professores em cursos de licenciatura e levam à sobreposição de conteúdos de Língua Portuguesa e das outras disciplinas aqui consideradas, caso não haja um planejamento didático que preveja ações complementares para elas.

De fato, de acordo com Possenti e Ilari (1992), o ensino de línguas deve ser muito menos o de fornecer técnicas do tipo como ensinar sintaxe a partir de uma certa teoria sintática ou como trabalhar o texto a partir de uma certa teoria da compreensão. Trata-se de

\begin{abstract}
Buscar nas diversas teorias princípios capazes de combinar-se numa concepção minimamente consistente de língua e de aprendizagem: o estruturalismo convenceu-nos de que todas as línguas (todos os dialetos) são iguais; a GGT acostumou-nos a pensar numa gramática internalizada, responsável por nosso desempenho linguístico; a sociolinguística mostrou-nos que os falantes dominam gramáticas variáveis e têm sensibilidade para realizar alterações estilísticas requeridas pelos diferentes contextos; as teorias interacionistas mais recentes nos lembram a todo o momento que falamos para um interlocutor real, com a consequência, entre outras, de que escrever para ser lido é natural, mas é artificial escrever por escrever; esses princípios hipotéticos [...] apontam para um conjunto de atitudes pelas quais o ensino de língua materna se aproxima ao máximo do uso real e das condições naturais de aprendizado da língua. (POSSENTI E ILARI 1992, p. 12).
\end{abstract}

Lembramos que Língua Portuguesa foi considerada área de estudo em 1971. O parecer número 853/71 do Conselho Federal de Educação fixa o núcleo comum para os currículos do ensino do $1^{\circ}$ e $2^{\circ}$ graus e a doutrina do currículo na Lei 5.6972, conforme Brasil (1972). No artigo $5^{\circ}$ desse parecer, afirma-se que nas séries iniciais, sem ultrapassar a quinta, a língua será desenvolvida sob a forma de Comunicação e Expressão em Língua Portuguesa, tratada predominantemente como atividade; em seguida, até o fim desse grau, sob a forma de Comunicação em Língua Portuguesa, tratada predominantemente como área de estudo; e no ensino do $2^{\circ}$ grau, sob a forma de Língua Portuguesa e Literatura Brasileira, tratada predominantemente como disciplina. Prioriza-se formalmente desde então, portanto, o ensino da língua materna centrado em seus aspectos funcionais e comunicativos, nos dois graus de ensino.

De acordo com os Parâmetros Curriculares Nacionais (PCN) para o terceiro e quarto ciclos ( $5^{\mathrm{a}}$ a 8 séries) do ensino fundamental de língua portuguesa, 
[...] a unidade básica do ensino só pode ser o texto.

Os textos organizam-se sempre dentro de certas restrições de natureza temática, composicional e estilística, que os caracterizam como pertencentes a este ou aquele gênero.

Desse modo, a noção de gênero, constitutiva do texto, precisa ser tomada como objeto de ensino. (BRASIL, 1998, p. 23)

Interpretamos que, de acordo este documento, "a língua é [...] uma forma de ação social e histórica que, ao dizer, também constitui a realidade [...]” (MARCUSCHI, 2002, p. 23). E que a comunicação verbal só é possível através de algum gênero e de algum texto. Recomenda-se, portanto, o ensino da língua em uso, concretizada em textos escritos em diferentes gêneros, de acordo com as diversas esferas de interação discursiva que os instituem.

Essa posição é assumida por autores que conceituam a língua de acordo com os seus aspectos discursivos e enunciativos, e não apenas de acordo com as suas formas composicionais. O que está de acordo com o pensamento bakhtiniano sobre a questão da língua, constituída e constitutiva de um sujeito vivo, situado histórica e culturalmente, e fundada em usos em forma de enunciados. Esses, embora concretos e únicos, refletem as condições específicas e as finalidades das esferas da atividade humana a partir do seu conteúdo temático, estilo verbal e de construção composicional, que se fundam no todo do enunciado. "Cada esfera da utilização da língua elabora os seus tipos relativamente estáveis de enunciados, sendo que isso que denominamos gêneros do discurso". (BAKHTIN, 1992, p. 279).

Porém, se a unidade de ensino de português precisa ser o texto oral e escrito filiado a algum gênero, conforme recomendam os PCN, por que haver uma segunda disciplina denominada Redação, ou Leitura e Produção de Textos, ou Letramento Linguístico etc., para o professor ensinar a ler e a escrever no Ensino Fundamental II?

Vimos que dois professores defendem que seja feito um trabalho interdisciplinar, baseado em textos envolvendo Língua Portuguesa, Redação e até disciplinas de outras áreas de ensino, mas ainda como unidades curriculares distintas. E nenhum deles argumenta claramente que Língua Portuguesa e Redação devem ser uma só disciplina, pois os professores entendem que precisam seguir as diretrizes do sistema de ensino para o Ensino Fundamental II.

O motivo apontado por eles para a divisão da Área de Letras em duas disciplinas, no Ensino Fundamental II, são os aspectos gramaticais a serem ensinados, que fazem parte de Língua Portuguesa, enquanto Redação trata dos gêneros. Ao mesmo tempo, eles opinam que o estudo gramatical não deve ser visto "como um fim", e que deve sair do texto e a ele retornar, segundo um dos depoimentos. Assim sendo, cremos que essa imprecisão de conteúdos e disciplinas nasce da imprecisão dos objetivos do ensino gramatical nos currículos de Língua Portuguesa nesse nível de ensino.

Perini (1997) faz um diagnóstico do ensino de gramática, que consideramos muito atual, e, entre alguns defeitos apontados, o autor argumenta que os seus objetivos estão mal colocados, já que o estudo da análise gramatical não é um dos instrumentos que levarão o estudante a escrever melhor, ter domínio da língua padrão escrita. Não se pode prometer isso, pois, se é necessário saber gramática para escrever bem, a recíproca deveria 
ser verdadeira, e não é. A partir daí, Perini (1997) aponta a necessidade de se redefinirem os objetivos do ensino de português, já que os alunos aprendem a escrever escrevendo, e a ler lendo, relendo, reescrevendo.

Um outro defeito apontado pelo autor é que a gramática tradicional carece de organização lógica, pois se funda na tradição gramatical, e não na gramática enquanto disciplina racional. Ele cita vários exemplos, como a definição de 'sujeito' como 'o ser sobre o qual se faz uma declaração', embora possa haver sujeito indeterminado, haver igualmente a noção de sujeito como aquele que pratica a ação e se poder fazer uma pergunta sobre o sujeito e não uma declaração. O aluno esperto abdica das definições e parte para a análise dos períodos, e no caso do exemplo citado, percebe que sujeito é o elemento com o qual o verbo concorda.

Brasil (1998, p. 28) compreende o ensino gramatical como atividade metalinguística, como proposto por Perini (1997), e recomenda a análise de aspectos gramaticais de textos produzidos e lidos em classe, pretendendo unir teoria e prática. Ou seja, na perspectiva de uma didática voltada para a produção e interpretação de textos, a atividade metalinguística, segundo esse documento, deve ser instrumento de apoio para a discussão dos aspectos da língua que o professor seleciona e ordena no curso do ensinoaprendizagem. Assim, não se justifica tratar o ensino gramatical desarticulado das práticas de linguagem.

E o que deve ser ensinado “[...] não responde às imposições de organização clássica de conteúdos na gramática escolar, mas aos aspectos que precisam ser tematizados em função das necessidades apresentadas pelos alunos nas atividades de produção, leitura e escuta de textos". Recomenda-se claramente, portanto, não se ter como referência a gramática tradicional, de cunho classificatório e prescritivo, e sim uma gramática descritiva. "Isso implica, muitas vezes, chegar a resultados diferentes daqueles obtidos pela gramática tradicional, cuja descrição, em muitos aspectos, não corresponde aos usos atuais da linguagem". (BRASIL, 1998, p. 29).

Porém, o que as entrevistas feitas com professores do Ensino Fundamental II de escolas públicas baianas nos mostraram é que o domínio teórico que eles e representantes do sistema de ensino têm sobre os objetivos do ensino da língua ainda não se transformou em domínio prático.

Vemos, na divisão de uma disciplina em duas, que os professores do Ensino Fundamental II trabalham em Língua Portuguesa com interpretação de textos seguida do estudo gramatical de seus períodos, de acordo com o que nos dizem em suas entrevistas. Para tanto, eles primeiramente fazem dinâmicas com textos, na maioria das vezes retirados do livro didático, assim como as questões de interpretação que se seguem. E a avaliação posterior dos alunos inclui o domínio de conteúdos da gramática tradicional, como, por exemplo, a classificação de substantivos etc.

Nessa cisão, portanto, a disciplina Língua Portuguesa não contempla o estudo do gênero a que se filia o texto, que, conforme prevê Brasil (1998) por meio dos PCN, precisa ser tomado como objeto de ensino. Mas contempla o ensino gramatical a partir do texto. E, com isso, a disciplina se afasta da noção de língua enquanto usos feitos por interlocutores reais, o que teoricamente se prevê, o que pode reforçar a ideia amplamente 
criticada pelos PCN e autores citados, dentre outros, de que, para aprender a língua, é necessário aprender a gramática. Tanto que quatro dos professores entrevistados chegam a comentar ligeiramente que muitos alunos têm dificuldades no aprendizado da língua, referindo-se ao aprendizado de regras da gramática tradicional.

Nesse contexto, é necessário reforçar o pressuposto de que o ensino gramatical é atividade metalinguística, cujo objetivo é oportunizar uma reflexão sobre a língua. É preciso também lembrar de Perini (1997), citado acima, quando argumenta que a matéria Gramática não se sustenta teoricamente com base nos estudos linguísticos, já que se funda historicamente na tradição gramatical, o que requer um olhar crítico sobre os seus postulados.

Nesse contexto, vale a pena citar Bagno (2012, p. 21), que, em sua gramática propositiva de uma pedagogia do português brasileiro, propõe não "uma descrição exaustiva e detalhada do PB, mas uma exposição daquilo que constitui conhecimentos necessários para um trabalho relevante e construtivo de educação linguística". Para tanto, estabelece como público-alvo, ou leitores potenciais, professores em formação ou já formados que exercem o magistério, pressupondo que esses tenham, de antemão, "um conhecimento básico da linguística moderna, suas principais correntes teóricas, conceitos e postulados", e "familiaridade com a doutrina gramatical tradicional [...]. Bagno (2012, p. 21).

Portanto, é recomendável que os professores possam ter como referência os conteúdos de uma gramática descritiva que dê conta dos aspectos que precisam ser abordados em função das necessidades apresentadas pelos alunos ao ler e escrever, como propõe como referência Brasil (1998). Para isso, é importante garantir-lhes, em sua formação, um conhecimento da gramática tradicional, para que possam criticá-la quando sua prescrição não corresponder, em algum aspecto, aos usos atuais do português escrito.

\section{PARA CONCLUIR}

Redação ou Leitura e Produção de Textos como disciplina distinta de Língua Portuguesa, ou algum projeto de leitura implantado nas escolas como parte do currículo, pode trazer a "leveza" de que nos fala uma professora mencionada anteriormente, sem o compromisso com o ensino da gramática tradicional, tarefa relegada à Língua Portuguesa. Ou mais liberdade de ação, como relatou outro professor. Só que a base das duas disciplinas são os textos escritos e ambas preveem a formação de leitores e redatores, ou seja, ambas têm um objetivo central comum.

$\mathrm{Na}$ verdade, o que existe é uma disciplina única, fundada na concepção da língua enquanto um conjunto de práticas sociais, e que tem um objetivo primeiro, central, que é o de ampliar o repertório linguístico dos alunos através de diferentes usos orais da língua e do aprendizado da leitura e produção de textos escritos de diferentes gêneros do discurso. Além de um segundo objetivo, que não pode ser confundido com o primeiro, que é o de propiciar uma reflexão sobre a língua através da análise gramatical dos textos escritos que são lidos e produzidos pelos alunos. 
As incongruências dos currículos para o ensino de português, portanto, refletem os defeitos dos objetivos do ensino de língua que estão postos pelo sistema escolar e que se confundem na imprecisão de duas disciplinas ou uma disciplina só. Desse modo, esses objetivos precisam ser revistos a partir de uma transposição entre o domínio teórico que os professores possuem sobre a língua e o domínio prático do ensino nos diferentes contextos escolares.

\section{REFERÊNCIAS:}

BAgNO, M. Gramática Pedagógica do Português Brasileiro. SP: Parábola, 2012.

BAKHTIN, Mikhail. Os gêneros do discurso. In: Estética da criação verbal. (Tradução feita a partir do francês de Maria Ermantina Galvão G. Pereira; revisão da tradução Marina Appenzeller). 2. ed. São Paulo: Martins Fontes, 1992.

BRASIL. Secretaria de Educação Fundamental. Parâmetros curriculares nacionais: terceiro e quarto ciclos do ensino fundamental: língua portuguesa/ Secretaria de Educação Fundamental. Brasília: MEC/SEF, 1998. 106 p. Disponível em: < http://portal.mec.gov.br/seb/arquivos/pdf/portugues.pdf>. Acesso em 12 de Jul 2017.

BRASIL Parecer n853/71 de 12 de nov.1971. Fixa o núcleo comum para os currículos do ensino do $1^{\circ}$ e $2^{\circ}$ graus e a doutrina do currículo na Lei 5.692. In: Habilitações profissionais no ensino do $2^{\circ}$ grau. Brasília, Ed. Expressão e Cultura, 1972

MARCUSCHI, L. A; DIONÍSIO, MACHADO E BEZERRA, (org). Gêneros textuais: definição e funcionalidade. In: Gêneros textuais e ensino. 2. ed. Rio de Janeiro: Lucerna, 2002. PCN / MED / SEF, 1998.

PERINI, Mário A. Sofrendo a gramática: a matéria que ninguém aprende. In: Sofrendo a gramática: Ensaios sobre a linguagem. $3^{a}$ ed. São Paulo: Ática, 1997.

POSSENTI E ILARI In: KIRST, Marta \& CLEMENTE, Ivo. Linguística Aplicada ao Ensino de Português. 2. ed. Porto Alegre. Mercado de Aberto. 1992, p. 12.

Recebido em: 05/06/2017

Aprovado em: 23/07/2017

Publicado em: 01/02/2018 